\section{Almas delirantes (1925) por Luís Cebola: a poética da psique humana e o médico como mediador entre o universo da doença mental e a sociedade}

Almas delirantes (1925) by Luís Cebola: the poetics of the human psyche and the physician as mediator between the universe of mental illness and society

Denise Pereira

Membra do doutorado, Centro Interuniversitário de História e Filosofia das Ciências/Universidade de Lisboa e Universidade Nova de Lisboa. Caparica - Portugal

denise.b.pereira@gmail.com
PEREIRA, Denise. Almas delirantes (1925) por Luís Cebola: a poética da psique humana e o médico como mediador entre o universo da doença mental e a sociedade. História, Ciências, SaúdeManguinhos, Rio de Janeiro, v.25, n.1, jan.-mar. 2018, p.143-161.

\section{Resumo}

Luís Cebola publicou em 1925 o volume Almas delirantes, onde apresentava diversas psicopatologias não de um ponto de vista médico-científico, mas elaborando retratos metafóricos e líricos, demonstrando que a perceção que tinha sobre os doentes ultrapassava a de objetos de estudo científico, constituindo um processo de identificação, empatia e compaixão. Cebola definia os estados psicopatológicos por oposição à normalidade, salientando, todavia, que estas doenças poderiam surgir em qualquer indivíduo, funcionando o livro simultaneamente como um aviso aos leitores. O volume permitia-lhe ainda divulgar o Museu da Loucura, que criara na Casa de Saúde do Telhal, e a arte dos seus pacientes, colocando-se assim na posição de mensageiro entre o universo fechado do hospital psiquiátrico e a sociedade portuguesa.

Palavras-chave: Luís Cebola (1876-1967); Museu da Loucura; psiquiatria; Casa de Saúde do Telhal; saúde mental.

\section{Abstract}

Lúis Cebola's 1925 work Almas delirantes [Delusional Souls] presented various psychopathologies through metaphorical and lyrical portraits rather than from a medical/ scientific point of view, showing that he perceived his patients as more than objects of scientific study in a process of identification, empathy, and compassion. Cebola defined psychopathological states according to contrast with normality, but stressed that these diseases could arise in any individual, and the book simultaneously acted as a warning to readers. The text also publicized the Museum of Madness [Museu da Loucura], which he created at the Casa de Saúde do Telhal, and the art produced by his patients, positioning himself as a messenger between the closed universe of the psychiatric hospital and Portuguese society.

Keywords: Luís Cebola (1876-1967); Museu da Loucura; psychiatry; Casa de Saúde do Telhal; mental health. 
$\mathrm{L}$ uís Cebola (1876-1967) tornou-se, em 1911, diretor clínico de uma das instituições \lrcorner psiquiátricas de maior relevo para o desenvolvimento da psiquiatria enquanto especialidade clínica, em Portugal: a Casa de Saúde do Telhal (CST), localizada em Sintra (Cebola, 1957, p.57-58). Este hospital pertence à Ordem Hospitaleira dos Irmãos de São João de Deus e foi fundado em 1893. Após a implantação da República, a 15 de outubro de 1911, Afonso Costa visitou esta instituição, tendo autorizado os membros da Ordem a prosseguir com o seu trabalho de enfermagem psiquiátrica, impondo, como condições, o abandono do uso do hábito religioso e a sujeição a inspeções oficiais periódicas do funcionamento do hospital, por parte de delegados do governo (O ministro..., 24 out. 1910, p.522; Serrão, 1995, p.55). A propriedade onde a CST se encontra edificada foi adquirida, a título pessoal, por Bento Menni (1841-1914), cidadão italiano e membro da Ordem Hospitaleira de São João de Deus (OHSJD), e não pela ordem religiosa, o que impossibilitou que o Estado pudesse reclamar direitos sobre ela, justificando a insistência de Afonso Costa em colocar na posição de diretor clínico deste hospital alguém com simpatias republicanas (Lavajo, 2003, p.70, 92).

Em consequência da Primeira Guerra Mundial, surgiu um elevado número de perturbações psíquicas nos militares que haviam servido o país no conflito. A CST foi subsequentemente selecionada pelo Ministério da Guerra para receber e tratar esses pacientes, com compensações estatais. Foi protocolado um acordo, contemplando subsídios à instituição por parte do Estado, que foi deveras importante para o desenvolvimento do hospital, uma vez que esses pagamentos permitiram sua ampliação e o melhoramento das infraestruturas já existentes (Borges et al., 2009, p.113). Durante a década de 1930, a CST foi novamente designada pelo Exército português, para ministrar, como hospital militar, os tratamentos das perturbações psiquiátricas dos membros do Exército (Carvalho, 1993, p.226). Esses doentes estiveram sob a responsabilidade de Luís Cebola até 1933, altura em que foi admitido neste hospital o doutor Diogo Furtado, para assumir o tratamento dos oficiais (Borges et al., 2009, p.22).

Luís Cebola formou-se na Escola Médico-Cirúrgica de Lisboa, de 1899 a 1906 (Serrano, 1900, p.41; 1907, p.100), tendo preparado a sua tese inaugural sob a orientação do professor Miguel Bombarda (1851-1910). Essa tese, denominada A mentalidade dos epilépticos, teve por base a reunião e análise de documentos de expressão artística dos doentes epiléticos do Hospital de Rilhafoles ${ }^{1}$ com o objetivo de encontrar alguma lei psicopatológica comum a essas produções (Cebola, 1906, p.33, 72). Manteve-se no cargo de diretor clínico da CST até 1949. A sua convicção inabalável nos ideais republicanos valeu-lhe a nomeação para diretor clínico da CST, pelo próprio Afonso Costa (1871-1937), em nome do Governo Provisório da República Portuguesa (Borges et al., 2009, p.14; Cebola, 1957, p.57-58).

Curiosamente, Cebola foi até o momento uma figura secundária da história da psiquiatria portuguesa, apesar de ter desempenhado o cargo de diretor clínico de uma instituição de relevo e de ter publicado 23 obras de carácter multifacetado, muito divulgadas pela imprensa portuguesa. Foi uma figura muito plural, apresentando nas suas obras e escritos publicados fortes interconexões entre temas médicos e as suas preocupações de carácter sociopolítico. Publicou numerosos artigos de popularização científica e crítica política em jornais diários, bem como seis coletâneas de poesia, um volume de contos, uma autobiografia e um livro de viagens. Na sua obra escrita é impossível discernir fronteiras concretas entre as suas 
diversas facetas, procurando sempre incluir o poeta, o republicano, o crítico sociopolítico e o psiquiatra de espírito positivista, quer por meio da linguagem escolhida, como dos temas problematizados.

Alguns estudos dedicados à figura deste psiquiatra foram preparados por investigadores cujo trabalho se encontra de alguma forma relacionado com a OHSJD, a ordem religiosa que administra e dirige a CST. Em 2009, foi publicada uma monografia sobre Luís Cebola pelo Centro de Estudos Interdisciplinares do Século XX (Ceis20), da autoria de Aires Gameiro, Augusto Moutinho Borges, Ana Mateus Cardoso e Fernando de Oliveira, intitulada Um republicano no convento (Borges et al., 2009). Essa monografia inclui a visão pessoal de Gameiro - irmão da OHSJD - acerca de Luís Cebola, que conheceu pessoalmente enquanto este era diretor clínico da CST. Os quatro autores questionam o porquê deste psiquiatra, juntamente com a própria instituição hospitalar da CST, ter sido largamente negligenciado pela história da psiquiatra portuguesa, salientando a necessidade de desenvolver estudos mais pormenorizados sobre a vida e a prática profissional de Cebola, bem como da instituição. Os autores referem igualmente a escassez de documentação relativa aos primeiros anos de Luís Cebola, como diretor clínico, na CST. Subsequentemente, Gameiro (nov. 2009, p.126-132) publicou um artigo sobre o psiquiatra, no qual abordou temas semelhantes aos previamente explorados na referida monografia, intitulado "Evocação de um médico esquecido, o Dr. Luís Cebola pioneiro da Ocupação Ergoterápica na Casa de Saúde do Telhal, da Ordem Hospitaleira de São João de Deus". Ambas as publicações oferecem uma visão global da personalidade e ideologia de Cebola, bem como providenciam informação acerca do seu trabalho como director clínico na CST, embora de forma não minuciosa e detalhada.

Das 23 obras publicadas, duas são fortemente baseadas na análise clínica e psicológica dos seus doentes: Almas delirantes (1925) - o volume aqui em análise - e Quando desci ao inferno: contos psicopatológicos (1956). Esses volumes exibem retratos dos doentes mentais que ultrapassam a simples enumeração sintomatológica. Pela sua leitura, compreendemos que o psiquiatra possuía uma enorme empatia para com os estados mentais dos pacientes, aliada a uma forte retórica propagandista de ideologias de reforma social e política, conferindo a essas obras um discernimento invulgar, uma elevada perspicácia no esclarecimento de questões relacionadas com a perceção social e clínica da doença mental, durante a primeira metade do século XX. A análise desses trabalhos possibilita um melhor entendimento sobre a relação entre o conhecimento científico e médico e a polis, isto é, a permeabilidade de ideias clínicas em contextos sociais múltiplos. Do mesmo modo, a elucidação dos recursos retóricos por meio dos quais Cebola se apresenta aos leitores permite ao historiador identificar as premissas e pressupostos aceites implicitamente, ou sujeitos à controvérsia, em relação à figura do homem de ciência e do clínico, em Portugal durante a época em estudo.

A escolha da obra aqui em análise resultou do fato de esta ser uma das suas obras em que é mais evidente a conjugação entre as facetas do psiquiatra e do poeta, marcantes na definição da personalidade do médico, bem como das suas escolhas metodológicas como diretor clínico, e também por esta ser a sua primeira publicação dedicada a um tema psiquiátrico, onde é já claro o estilo de escrita metafórico que permeará todos os seus volumes clínicos, bem como a temática primordial de todos esses volumes: a análise psicológica do 
doente mental e a contextualização da sua posição social. Infelizmente pouco se conhece sobre o impacto que esta obra teve na comunidade médica da época, bem como no público em geral. Contudo, não passou indiferente à imprensa portuguesa, sendo muito elogiada em artigos de opinião em jornais como O Século (2 set. 1925) e o Diário de Notícias (22 jul. 1925, p.2). Neste último pode ler-se:

O autor deste livro é um psiquiatra distinto que há muitos anos dedica toda a sua ciência e todo o seu amor àqueles que taras hereditárias, tragédias da vida, desequilíbrios nervosos e outras causas lançaram no abismo da loucura. Almas delirantes são um valiosíssimo documento do seu saber e da elevação e carinho com que se entrega ao ramo da ciência a que se consagrou.

O objetivo deste artigo é o de contribuir para uma melhor percepção dessa figura - tão relevante no desenvolvimento da psiquiatria portuguesa, todavia muito secundária na literatura da história da disciplina, bem como misteriosa pela escassez de documentação pessoal existente - por meio da análise histórica e literária de um dos seus volumes multifacetados.

\section{Almas delirantes (1925)}

Vinte anos depois de iniciar a sua prática como psiquiatra, Luís Cebola publicava a obra Almas delirantes, dedicada à psique dos doentes mentais e editada pela Livraria Central Editora, localizada na avenida Almirante Reis, em Lisboa, propriedade do editor Gomes de Carvalho (1867-1952). ${ }^{2}$ Este último editou sete obras de Luís Cebola, tendo escrito a explicação prévia da sua obra Psiquiatria social (1931), na qual tecia grandes elogios ao psiquiatra e amigo: "pessoa competentíssima, que até hoje em Portugal se tem realizado, em favor dos alienados" e alguém que se poderia orgulhar de "haver sido o primeiro médico português, que depois de estudar lá fora as modernas modalidades da assistência prestada aos doentes de espírito", bem como de em seguida as divulgar, estimulando desse modo os superintendentes das instituições psiquiátricas nacionais (Cebola, 1931, explicação prévia).

Em Almas delirantes, Cebola (1925, proêmio) definia, da seguinte forma, o público-alvo ao qual este se destinava e o objetivo pretendido com a publicação:

Foram estas impressões colhidas nos departamentos da Loucura, que me sugeriram este livro, destinado àqueles que os desconhecem. Acharão nele algumas das mil facetas dos espíritos que desvairam. Livro de curiosidade e de ensinamento, deverá servir de aviso aos que andam às cegas nos caminhos eriçados de precipícios, donde só lhes é possível sair, para a escuridão do manicômio ou para a algidez do cemitério.

Este parágrafo evidenciava uma visão pessimista em relação à possibilidade de recuperação por parte dos doentes mentais. Todavia, sugeria, de modo implícito, que a obra teria a capacidade de alertar todos os que se encontrassem nas fases iniciais de desenvolvimento de uma perturbação psiquiátrica, procurando possivelmente, desse modo, estimular os leitores, que se identificassem com as descrições apresentadas, a solicitar um médico, de forma a evitar o destino trágico e irreversível retratado. 
Ao longo da obra, o psiquiatra apresentava retratos das diversas psicopatologias que observara ao longo da sua prática clínica não de um ponto de vista médico-científico, isto é, não apresentava descrições sintomatológicas das patologias nem quaisquer sugestões terapêuticas. Ao invés, elaborava, sim, retratos destas doenças recorrendo à metáfora, fazendo uso de uma linguagem muito lírica, o que lhe permitia aumentar a carga dramática dos mesmos. Logo no proêmio, Cebola recordava aos leitores que o destino destes "indigentes de sol, de amor e de energia" era o esquecimento, ainda em vida, quer por parte dos seus amigos e familiares quer por eles mesmos, na grande maioria das vezes: "A miséria suprema das consciências apagadas. O esquecimento. A cinza. O túmulo. Nada" (Cebola, 1925, proêmio).

Embora a hereditariedade fosse a causa apontada por Cebola para a origem das doenças da psique, esta linguagem metafórica permitia-lhe demonstrar a fragilidade da saúde mental, bem como evidenciar o mistério que as psicopatologias ainda representavam para a psiquiatria da época: o aparecimento das doenças da mente era por vezes tão repentino e inesperado que parecia resultar da intervenção de criaturas sobrenaturais. Por exemplo, na descrição dos doentes viciados em substâncias tóxicas, Cebola (1925, p.33) escrevia: "Como se fossem atraídos e levados por um duende ao antro do Vício, alguns espíritos, portadores de maléficas heranças, deixam-se arrebatar pela sua tendência ao abuso de tóxicos".

Outro exemplo de como a linguagem simbólica lhe permitia transmitir o drama da doença mental, enquanto fenômeno que em certos casos apagava por completo a humanidade dos seus pacientes, era o uso de figuras mitológicas, como Prometeu, o criador do processo civilizacional, símbolo do engenho e da criatividade humanas: "E, a destacarem-se no circo de tantas máscaras bizarras, erguem-se aquelas cujas linhas apagadas, indefinidas, lhes dão a aparência de criaturas esfíngicas, fantasmáticas, onde jamais se viu crepitar o fogo de Prometeu" (Cebola, 1925, proêmio).

\section{O conceito de felicidade e a doença mental}

Para além de apresentar diversos retratos da doença mental, ilustrando os "departamentos da loucura" (Cebola, 1925, proêmio) - nas palavras do próprio psiquiatra -, Cebola apresentava as suas teorias sobre a origem das perturbações da mente. No primeiro capítulo, intitulado "Onde se encontra a felicidade", sugeria que a "ânsia dos dias esplendorosos" teria como consequência o "desvairo dos espíritos". O desejo de atingir um estado permanente de felicidade e bem-estar, resultando em "desilusão", estaria nas origens da doença mental. A saúde mental apenas poderia conservar-se, afirmava, por meio da consciência da transitoriedade do sentimento de felicidade. O próprio confessava ter-se sentido atraído por essa ideia de escapar eternamente à dor e ao desgosto, tendo, contudo, recusado esse "canto da sereia", reconhecendo que um estado permanente de felicidade apenas existe na patologia:

A sereia canta à beira da estrada. Entra em nosso lar, espargindo flores e matinando auroras. Mas quando tentamos prendê-la num amplexo carinhoso e grato, foge para os campos ignorados, a rir, a rir da nossa ingenuidade. Some-se a miragem e o deserto fica - para muitos esbraseante, árido, interminável... ... Falei com ela. Quase lhe confessei a 
minha admiração, ao vê-la sobraçar uma cornucópia inesgotável de prazeres; mas não a quis. Voltei para casa, deixando-a na sua verdadeira morada (Cebola, 1925, p.16-18).

Os megalômanos procurariam evitar a desilusão, assim como a angústia dela resultante, isolando-se num universo próprio, abandonando a realidade, atingindo um estado de felicidade permanente. Todavia, esta era apenas uma ilusão, um dos sintomas da sua psicopatologia:

Não existe, pois, a Felicidade. Todavia, eu já a vi no mundo dos loucos. Encontrei-a nos megalômanos. Nestes, sim, é que ela floresce de vida exuberante. Os delirantes de grandezas julgam-se tão felizes, que não compreendem o sofrimento. São os senhores absolutos da Felicidade absoluta (Cebola, 1925, p.17).

Neste capítulo, Cebola, na qualidade de médico psiquiatra, definia aquele que seria o estado normal por oposição ao estado psicopatológico. O ser humano normal era aquele que não abandonava a realidade, o que não se refugiava em ilusões, enfrentando estoicamente a dor, reconhecendo-a como consequência inevitável de estarmos vivos.

A aceitação de que o próprio se sentira atraído pela ideia de atingir um estado de felicidade permanente aproximava-o dos leitores e dos próprios doentes, demonstrando, assim, que estabelecia uma relação de empatia para com estes últimos, compreendendo os seus sentimentos, identificando-se com eles até certo grau. O retrato que o seu colega da CST, Meira de Carvalho (1980, p.127), elaborava de Cebola, é compatível com essa imagem de que o clínico procurava humanizar a sua relação com os doentes:

Os doentes menos agitados eram mantidos por grande grupo de enfermeiros e a visita começava, fazendo-me lembrar uma revista militar. Em vez de continência era com o aperto de mão, um a um, em fila indiana, que o Dr. Cebola cumprimentava com o seu risinho característico e palmadinha nas costas.

Apesar de Carvalho descrever este ritual comparando-o à disciplina militar, a forma como retrata a postura de Cebola durante essas visitas médicas às enfermarias do Telhal permite-nos imaginar um homem simpático e afetuoso, dentro do que seria possível, tendo em conta a agressividade expressa por muitos desses doentes.

Já Alberto da Cunha Dias (1886-1947), ${ }^{3}$ advogado que esteve internado na CST durante alguns dias e que se dizia injustamente diagnosticado por médicos como António Flores (1833-1957), , Júlio de Matos ${ }^{5}$ e o próprio Cebola, referindo-se a todos eles com raiva e sarcasmo, chamava-lhe "Cebolinhas". Sobre o seu internamento no Telhal escrevia:

Tem que o Cebola, o mesmo, o poeta, o Cebolinhas como sempre lhe chamei, é o diretor clínico do Manicômio do Telhal. E eu que nunca o tinha visto, vi-o e ouvi-o. ... Pois estive no Telhal catorze dias, e ouvi oito sonetos ao Cebolinhas, oito! ... Eu, foi em Agosto de 1916, ouvi os sonetos ao próprio. Recitou-mos ele, o Cebolinhas, de pé na cela do manicômio com gesto largo e de fraque. Só o fraque! ... Olhe leitor, antes de o ler, veja-o e se o vir de fraque já não o lê. E salva-se! os sonetos do Cebola filho, O Cebolinha, são mortais. Quem os lê ou os ouve morre. E precisamente porque eu fui a primeira pessoa que escapou, é que pela primeira vez sou a primeira pessoa que falo deles ao leitor. E estão para aí impressos! (Dias, 1919, p.67-69). 
Apesar de a descrição do advogado pretender ser insultuosa para com o psiquiatra, ela demonstra, de certo modo, que Cebola procurava estabelecer uma relação de partilha com os seus doentes. Ainda que esta partilha fosse forçada - no caso narrado pelo advogado documentando o desequilíbrio da relação estabelecida entre o psiquiatra e alguns doentes, percebemos que Cebola não só admitia que os seus pacientes mantinham intacta - até certo ponto - a capacidade de apreciar os poemas, mas também que ele não procurava distanciar-se completamente dos seus doentes, uma vez que com eles partilhava alguma da sua intimidade, isto é, as suas criações poéticas.

\section{"E a farândola continuava a sua marcha, berrante de originalidade": razão e moralidade dos doentes mentais}

Embora, em grande parte desta obra, Cebola se referisse à loucura enquanto fenômeno fatal e irreversível, no capítulo "Sátira e filosofia" oferece-nos outra visão da psicopatologia. Baseando-se na sua experiência pessoal, enquanto diretor clínico da CST, o psiquiatra elaborou uma visão mais plural desses seres humanos, revelando que a doença mental não destruía na íntegra as capacidades cognitivas, criativas e emotivas. Por esse motivo, os doentes podiam continuar a desempenhar algumas funções sociais e participar em empreendimentos laborais e artísticos, dentro do hospital psiquiátrico. Admitia que os leigos desconhecessem que "são bastante numerosos os [loucos] que conservam relativa lucidez", e pormenorizava:

Orientam-se no tempo, lugar e ambiente. Denunciam os seus desejos e apetites, defendendo-os com veemência. Criticam o procedimento incorreto ou menos cortês daqueles que se presumem de sensatos. Emitem opiniões razoáveis sobre diferentes assuntos. Aplicam a sua atividade em trabalhos úteis. Traçam planos engenhosos. Concebem e realizam obras de arte. $\mathrm{E}$ até a ironia e o conceito cintilam no cérebro d'alguns alienados (Cebola, 1925, p.51).

O psiquiatra aproveitava então para estabelecer uma crítica aos indivíduos normais, afirmando que, por vezes, os loucos conservavam uma maior quantidade de sensatez e bom senso do que estes. Num parágrafo subsequente afirmava mesmo: "Recordando a vida social, ataviada de falsos ouropéis, quantas vezes, ao sair da casa dos loucos, eu fico a pensar se eles, os detentores das verdades cruas, não serão também, neste mundo, as únicas pessoas de juízo" (Cebola, 1925, p.52).

Neste parágrafo era evidente o quão Cebola era sensível à desonestidade e hipocrisia, temas que marcaram algumas das suas obras de crítica sociopolítica, como Estado Novo e República (1955) ou Quando desci ao inferno: contos psicopatológicos (1956). ${ }^{6} \mathrm{O}$ elogio à personalidade crua dos doentes mentais permitia-lhe criticar a sociedade sua contemporânea, romantizando, desse modo, a figura do louco enquanto símbolo do expoente máximo do homem livre. A figura do louco funcionava como uma fonte de inspiração para o próprio psiquiatra, oferecendo-lhe coragem para estabelecer as suas críticas sociopolíticas na imprensa, bem como para assumir as suas convicções. Em certa medida, Cebola parece ter encontrado consolo na companhia dos seus doentes, e no ambiente hostil e trágico do 
hospital psiquiátrico, uma espécie de refúgio da vida "real", ambiente esse onde era sempre detentor da última palavra - no diagnóstico e programa terapêutico - e, onde, apesar da imprevisibilidade do quotidiano, a sua posição não era posta em causa, uma vez que era ele o diretor clínico do estabelecimento.

Ao contrário das suas obras de crítica sociopolítica, ${ }^{7}$ nas quais evidencia a incapacidade social dos doentes mentais e o perigo que representam para a estabilidade do tecido social por meio do uso da teoria da degeneração -, nesse volume, inspirado na sua experiência como diretor clínico da CST, o médico apresentava um retrato da doença mental de certo modo mais otimista, evidenciando não apenas as capacidades cognitivas que eram preservadas nos doentes, bem como certos sintomas da alienação que permitiam aos loucos suportar o drama da existência humana, de formas não acessíveis aos indivíduos normais, como, por exemplo, a capacidade de se iludirem a tal ponto que deixavam de sentir a desilusão natural da vida real.

Esse volume revela, de certo modo, a forma como o próprio Cebola encarava a sua prática clínica, isto é, o privilégio da terapia ocupacional e pela arte. O seu enfoque nessas práticas terapêuticas era sem dúvida motivado pela crença na possibilidade de reabilitação dos doentes, e ainda na conservação da sua inteligência, até certo grau. Num texto escrito em 1944, para a revista Hospitalidade, ${ }^{8}$ Cebola $(1945$, p.163) evidenciava o papel regenerador da ergoterapia:

Quem, nos dias úteis, visitar a Casa de Saúde do Telhal, há-de surpreender grupos de doentes - esquizofrénicos, débeis mentais, hipomaníacos, ${ }^{9}$ alcoólicos, e outros - que trabalham alegres em pleno ar livre; e guardará decerto, a melhor impressão do que ali viu, isto é: diligenciarmos, há dezenas de anos, subtrair os enfermos às torturas dos seus delírios alucinatórios, reintegrando-os, pela laborterapia, na vida social.

De forma a demonstrar como os doentes mentais conservavam determinadas capacidades intelectuais intactas, Cebola apoiava-se em determinadas passagens de escritos dos seus pacientes. As passagens selecionadas não causam espanto no leitor por serem lógicas e comuns, mas por oferecerem metáforas inovadoras e, de certo modo, poéticas sobre fenômenos quotidianos ou sentimentos - "O manicômio é um cemitério sem sepulturas, onde os mortos passeiam o seu infortúnio" (Cebola, 1925, p.52); "As lágrimas são o sangue do coração" (p.53); "A alma é um substantivo abstrato" (p.57) - ou por serem humorísticas - "Um bom homem é um boi-homem"; “- Boas entradas no Novo Ano! O louco referindose à sua alta e apontando-me a rua: - Boas Saídas!... Boas Saídas!” (p.57) -, revelando desse modo que os doentes mentais continuavam a processar os mesmos sentimentos que os homens comuns, conservando também a capacidade de refletir sobre si mesmos e acerca da realidade que os rodeava, ou de originar novas ideias, ainda que estivessem incapacitados de construir a sua vida de forma autônoma. Cebola demonstrava não só a sua sensibilidade, bem como a capacidade de demonstrar empatia para com os pensamentos e emoções dos seus doentes.

Embora algumas das frases selecionadas não pareçam fazer sentido, elas comprovam a existência de um universo interno, de um constante processamento do mundo exterior, documentando o funcionamento da razão, mesmo que partindo de pressupostos 
completamente diferentes dos que guiam o pensamento dos indivíduos normais. O fato de lhes dedicar um capítulo de 11 páginas, quando a maioria dos capítulos dessa obra é composta por três a quatro páginas, demonstra como Cebola valorizava esses breves diálogos estabelecidos com os doentes, algo que também transparece nas anotações transcritas na maioria dos seus processos clínicos (Pereira, 2015, p.64-100). Possivelmente, esses fragmentos de pensamento, para além de surpreendentes pelas associações de ideias incomuns, mas de certo modo lógicas, eram a única forma de o médico sentir que acedia, nem que momentaneamente, ao universo ideativo e emocional dos doentes, demonstrando, em certos casos, como os pacientes conservavam intactas as memórias do mundo real, pressagiando desse modo certamente alguma esperança em relação à sua recuperação.

Embora considerasse que os loucos conservavam alguma capacidade de raciocínio, o mesmo não era válido para a moralidade. O psiquiatra afirmava que os loucos a perdiam parcialmente e por completo, uma vez que "intoxicada a célula cerebral ou aderentes as meninges ou involucionado o encéfalo, a mentalidade" tornava-se "respectivamente obtusa, atardada e nula". A patologia, resultando na supressão dos "freios sociais", revelavase em "atos desonestos e sentimentos inferiores, ou de todo ausentes, como o egoísmo sórdido ou as paixões brutais". Este paralelo entre a imoralidade e a loucura permitia-lhe elaborar uma crítica à sociedade sua contemporânea, chegando mesmo a sugerir que esta estaria caminhando para o desenvolvimento de uma moralidade patológica: "Focando, de passagem, a nossa sociedade leviana, indisciplinada, corrupta e viciosa, ocorre perguntar: - Não será a moral dos loucos a moral do futuro?" (Cebola, 1925, p.70).

\section{Retrato de um doente mental: a imprevisibilidade da patologia}

Dedicando um capítulo de quatro páginas a um doente que estivera hospitalizado na CST, sofrendo de demência paralítica, ${ }^{10}$ ao qual chamava "História triste", demonstrava a imprevisibilidade da doença mental, bem como o seu poder destruidor. De acordo com o psiquiatra, teria conhecido esse doente "no apogeu da sua mocidade radiosa": nada na sua aparência física - "Alto, desempenado, insinuante, harmônico nas linhas de corporatura esbelta" -, bem como na sua constituição psicológica - "sobredoirava-lhe a plástica aprimorada, o espírito de escol, fino, maleável" e "sentimentos ternos" - indiciava a doença que viria a manifestar-se, pelo menos não aos leigos. Cebola salientava, todavia, que esse indivíduo exibia por vezes "ligeiros arrebatamentos um tudo ou nada pueris". Concluíra o seu curso universitário sem quaisquer problemas, período que lhe permitira desenvolver qualidades que já possuía como "brotar outras, latentes, de maior realce, para marcar situação de destaque na comunidade. O seu talento literário cintilara em verso e prosa de valia" (Cebola, 1925, p.81).

Toda a vida desse indivíduo fora promissora, até o aparecimento da patologia que o viria a vitimar durante o internamento. Quando foi detectada já estava num estádio avançado, sendo por isso incurável. Sobre a mesma, Cebola afirmava:"O período de invasão carretou-lhe o enfraquecimento psíquico, imperceptível aos leigos, não obstante as repetidas falhas com que beliscava as suas relações familiais, de profissão e sociedade" (Cebola, 1925, p.82). 
O contraste entre a vida bem-sucedida do seu paciente - com o qual estabelecera decerto um processo de identificação, uma vez que ele próprio se dedicava à escrita de poesia -, e a ruína que se seguira após a evolução da patologia, comoveram-no. De fato, essa história servia de exemplo aos leitores: um caso-clínico descrito com algum pormenor, revelando o antes e o depois da psicopatologia, de forma a demonstrar como todos os indivíduos internados, arrancados à sua normalidade, haviam sido homens comuns, alguns mesmo talentosos e atingindo sucessos acima da média da população. A loucura, à semelhança da morte, poderia cair sobre qualquer um de nós, independentemente da classe social ou do nível de desenvolvimento intelectual. Esta fronteira tênue entre a normalidade e a doença mental, patente na obra de Cebola, era notada pelo jornal O Século, que em 2 de setembro de 1925, num artigo de crítica a essa obra, escrevia: "O maior interesse de livros, como este, está na revelação curiosíssima dos aspectos do que poderíamos chamar a 'marca' fronteiriça entre a loucura e a saúde mental" (O Século, 2 set. 1925, p.2).

O convívio diário com essas histórias fatídicas, com o constante contraste entre períodos curtos de lucidez e momentos de esbatimento de personalidade, parece não ter tornado Cebola insensível ao sofrimento dos seus pacientes. Sobre o mesmo paciente Cebola (1925, p.83) escrevia:

Nas horas de lucidez, o coração me doia de o ver a chorar pelas filhas, ralado de saudades. E chegava a ser tão vivo o seu pesar, que me implorava de joelhos e beijandome as mãos, lhe fosse buscar as pequeninas. Diligenciei cumprir o seu desejo de moribundo para lhe abrir um oásis no seu deserto de funda consumição. Mas todos os meus esforços foram baldados! A esposa nunca prestou ouvidos aos seus nem aos meus rogos! E o inditoso poeta, morreu, quando alvorecia uma linda manhã de primavera.

A narrativa desse caso clínico permitia-lhe também publicar os poemas desse doente, uma vez que considerava tratar-se de uma enorme injustiça que tal indivíduo tivesse falecido sem ter tido a oportunidade de ver publicados os seus versos, de ser reconhecido pelo seu talento: "Nem um singelo epitáfio indica a sua pobre jazida! Apenas uma cruz se ergue sobre a sua sepultura anônima de infeliz poeta" (Cebola, 1925, p.83). Certamente por não ter acesso aos versos que o doente escrevera antes de ver as suas capacidades degradadas pela evolução da psicopatologia, Cebola transcrevia os poemas que haviam sido elaborados aquando do internamento no Telhal, um deles dedicado à sua esposa, de quem se havia divorciado antes de ser hospitalizado. Este último poema, intitulado "Alma da minha alma", aqui publicado, funcionava como uma mensagem endereçada pelo médico à esposa do paciente, demonstrativa da injustiça das suas ações para com o marido doente:

Tudo o que sou a mim próprio devo,

E ao amor gentil de uma só mulher,

Que a mim somente a mim prefere,

E para quem é tudo o que escrevo.

Mas ela é a alma de tudo o que hei escrito

$\mathrm{E}$ a mãe das filhinhas radiosas

Do nosso lar d'amor, santo e bendito (Cebola, 1925, p.97-98). 
Essas transcrições permitiam-lhe deixar para a posteridade os pensamentos desses homens excomungados da sociedade, mas com os quais partilhava parte significativa dos seus dias, e aos quais decidira dedicar a sua vida profissional. Tendo em conta a baixa percentagem de curas ou de melhorias verificadas nesses doentes, Cebola servia-os desse modo, fazendo justiça aos seus pensamentos, aos seus talentos, mesmo que modestos, apresentando-se como mensageiro entre o mundo dos "loucos" e o mundo dos indivíduos ditos normais. Essa comunicação constituía parte daquela que estabelecera como sendo a sua missão pessoal enquanto cidadão e médico.

\section{O Museu da Loucura}

O processo de documentação, bem como de conservação das criações artísticas elaboradas pelos doentes internados na CST, deu origem e culminou com a formação de um museu, durante a década de 1920. Um capítulo do volume Almas delirantes era dedicado ao dito museu, que funcionava como repositório dessas mesmas criações. Para além da transcrição integral de poemas, textos, cabeçalhos de jornais produzidos pelos doentes, anedotas e cartas, eram ainda incluídas fotografias das esculturas e desenhos. Essa recolha, além de amostra das obras realizadas e do poder criativo subjacente, intentava realçar a importância da análise das mesmas para a confirmação dos diagnósticos psicopatológicos:

Durante a minha assistência clínica naquele estabelecimento [Cebola refere-se aqui à Casa de Saúde do Telhal], tenho vindo a coligir os elementos que compõem o seu museu. Além de fornecerem aos profanos objeto de distração, contêm matéria interessantíssima para os cultores da psiquiatria. Constata-se, analisandoos, que a loucura não destrói sempre o sentimento estético e, em muitos casos, pelo contrário, os desperta ou os intensifica ... O estudo dos escritos e desenhos dos alienados tem alta importância - como especulação científica, rasgando aos mentalistas novos horizontes; como subsídio clinico, dando muitas vezes um sinal ecográfico, estereotípico literal, verbal ou gramatical, a chave dum diagnóstico; como esclarecimento precioso e quiçá definitivo, quando se debatem questões emaranhadas de medicina forense; e até como base da crítica de arte e do julgamento seguro dos personagens que vincaram soberanamente os traços psicológicos de uma época (Cebola, 1925, p.113-114).

Esse capítulo era o mais longo do volume, composto por 55 páginas. Apenas duas eram da autoria do próprio Cebola. As restantes continham a exposição das produções artísticas dos pacientes. Nenhum texto interpretativo acompanha essas transcrições, indicando-se apenas a categoria psicopatológica dos respetivos doentes. Como exemplo, apresentam-se os seguintes versos de um doente sobre a sua hospitalização na CST, incluindo mesmo a figura do próprio Cebola, bem como a sensação expressa pelo doente de ter sido enganado a quando do momento de internamento, referindo-se aos seus companheiros usando os termos "maluquinho" ou "dementado":

Quem espera finalmente?

Espero o Dr. Cebola.

Então espere-o ali, 


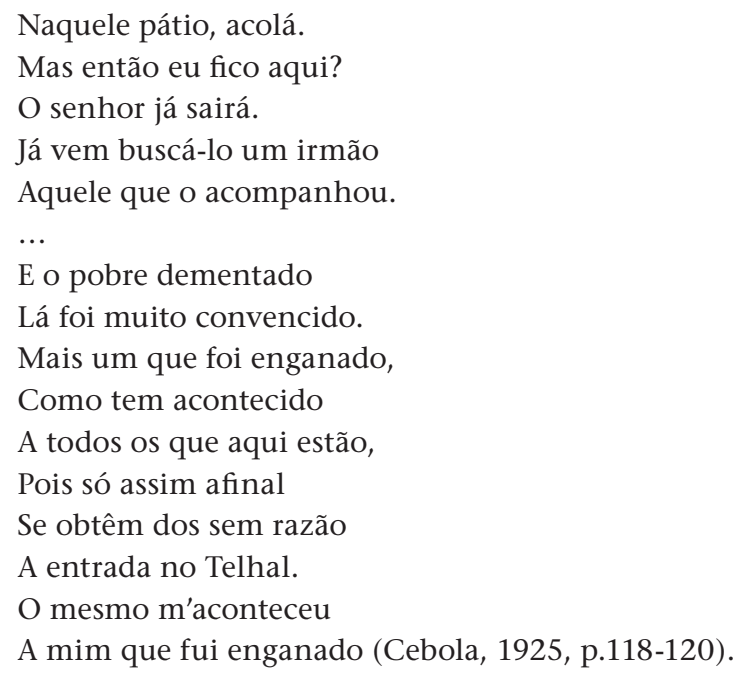

Em 1921, Walter Morgenthaler (1882-1965), psiquiatra suíço trabalhando no Hospital de Waldau, perto de Berna, publicou o volume Ein Geisteskranker als Künstler [Um doente mental como artista], um trabalho pioneiro descrevendo a análise estética dos trabalhos gráficos e musicais, bem como as produções esculturais do seu paciente Adolf Wölfi (1864-1930). Esse estudo tinha como foco o estilo do artista, em vez de procurar determinar os traços patológicos do trabalho do paciente (Peiry, 2001, p.20-23). Um ano mais tarde, Hans Prinzhorn (1886-1933), psiquiatra alemão, publicaria o volume Bildnerei der Geisteskranken [Arte dos doentes mentais]. Nesse volume, amplamente lido na época, o médico concluía que não existiam traços específicos que pudessem ser usados para distinguir entre a arte elaborada pelos doentes mentais com aptidões artísticas e a arte produzida por artistas sãos. A principal diferença notada pelo psiquiatra era a de que a representação da realidade na arte do doente esquizofrênico resultava de uma transformação forçada pela doença, enquanto no artista são essa transmutação da realidade resultava de um esforço e vontade conscientes. Esse estudo baseava-se na análise das obras reunidas na coleção do Hospital Psiquiátrico da Universidade de Heidelberg, constituída por um elevado espólio de obras produzidas pelos doentes dessa instituição e fundada por Emil Kraepelin. A maioria das obras analisadas nesse volume - desenhos, pinturas e esculturas - era da autoria de doentes (na maioria dos casos diagnosticados com esquizofrenia) sem qualquer treino ou formação artística (Peiry, 2001, p.20-23; Prinzhorn, 1972, p.VI-XV). Curiosamente, Cebola não refere nunca esses psiquiatras nem os seus volumes, todavia, é plausível afirmar, devido à influência que tiveram à época, que Cebola tenha tido conhecimento sobre essas obras, e que possam ter servido de inspiração para a criação do dito museu.

No Museu de São João de Deus - localizado na mesma quinta onde se encontra a CST - permanece atualmente o espólio deste Museu do Telhal (ou da Loucura), existindo mesmo uma exposição permanente, de algumas dessas obras, produzidas pelos doentes da instituição. 


\section{Os diálogos clínicos como meio de diagnóstico, fonte historiográfica e documentação do universo da doença mental}

Outro capítulo, do volume Almas delirantes, era dedicado aos diálogos estabelecidos com os pacientes, transcrevendo-os e associando o respetivo diagnóstico. De acordo com o clínico, esses diálogos eram registados na íntegra, de forma a auxiliar o "processo de investigação psicologica", enriquecendo o historial do paciente, bem como para arquivar dados históricos sobre as perturbações psicológicas da sua época, referindo-se a esse método como sendo "uma engenhosa maneira de historiar" (Cebola, 1925, p.173): "Os diálogos podem ser provocados ou espontâneos. Em ambos os casos, se deparam interessantes perspectivas de estudos futuros ou se colhem dados valiosos, para formular um juízo clínico, sobretudo quando são taquigrafados, como os que neste livro se publicam". O capítulo formado por essas transcrições é composto por 15 páginas, sendo, em conjunto com aquele dedicado ao museu e aos raciocínios dos doentes, atrás referidos, um dos capítulos mais volumosos dessa obra, definindo assim, na minha opinião, o objetivo subjacente a essa publicação: tornar visível a psique dos doentes mentais.

Foucault salientava, no prefácio de 1961 à sua Histoire de la folie à l'âge classique, como o homem moderno cessou a sua comunicação com os loucos, delegando tudo o que está relacionado com a doença mental ao médico psiquiatra, autoridade máxima na compreensão, diagnóstico e tratamento desses enfermos. O psiquiatra, afirma Foucault (2009, p.XXVIII), tornou-se assim o principal elo entre o mundo dos alienados e a restante sociedade, na medida que é um dos poucos membros do corpo social a conviver com os loucos e a dominar exclusivamente a linguagem científica alheia à compreensão dos leigos que designa tudo o que se relaciona com as perturbações da mente. A obra em análise remetia para a ideia do médico psiquiatra como figura mediadora entre esses dois universos, sendo fruto da prática clínica de Luís Cebola, e constituído por algumas histórias clínicas, por diálogos estabelecidos com os doentes, bem como por escritos elaborados por eles, tornava perceptível o seu universo ideativo, oferecendo retratos desses doentes que eram invisíveis ao público leigo, totalmente afastado da realidade da loucura nas suas diversas manifestações. Cebola, como autor dessa obra, assumia a missão de mensageiro dos doentes mentais, recuperando para eles o lugar que haviam perdido na sociedade, a partir do momento em que haviam sido hospitalizados. Afirmava a sua autoridade nesse processo, selecionando quais as produções artísticas e os escritos que eram revelados.

A partir do momento em que um doente dava entrada no hospital, não perdia apenas a sua credibilidade e, em grande parte, a incapacidade de provar a sua sanidade mental, como perdia muitos dos seus direitos civis. Segundo o decreto de maio de 1911, as visitas a qualquer alienado hospitalizado poderiam apenas ser autorizadas (ou negadas) pelo médico diretor ou seus substitutos. Ademais, os visitantes teriam de se fazer acompanhar de uma autorização por parte do requerente de internamento, isto é, aquele que havia requisitado a hospitalização: “As pessoas que desejarem visitar um doente pensionista, far-se-ão acompanhar de documento em que o requerente autorize a comunicação com o doente", citava o referido decreto (Portugal, 13 maio 1911, p.1949). Além disso, ditava ainda que toda a correspondência dos doentes estava sujeita à fiscalização por parte do médico 
diretor ou administrador, que poderia usá-la como elemento de estudo ou mesmo inutilizála, exceto se fosse dirigida ao inspetor do serviço de alienados. A correspondência externa dirigida ao doente não podia ser lida, apenas no caso de alegados alienados delinquentes. Contudo, o médico diretor podia decidir sustê-la, se o julgasse conveniente (Portugal, 13 maio 1911, p.1949-1950).

Ao contrário das referidas obras dos psiquiatras Hans Prinzhorn e Walter Morgenthaler, ao longo desse volume, Luís Cebola não tecia quaisquer considerações sobre os trabalhos criativos dos doentes, não fazia interpretações dos mesmos nem procurava comparar a sua qualidade estética com as dos artistas mentalmente sãos. Limitava-se, porém, a referir as semelhanças entre as criações artísticas dos doentes mentais e as dos "povos primitivos", a mencionar que alguns pacientes exibiam "provadas aptidões artísticas" ou a concluir pela sua "longa observação": "Que nos psicopatas escritores abundam as associações por assonância; donde ser grande o número dos que versejam. ... As tendências literárias, só reveladas nos estados de perturbação, se orientam geralmente no sentido da rima" (Cebola, 1925, p.113-114).

\section{O louco como símbolo dos extremos da experiência emocional humana: o cidadão mais feliz e mais miserável}

Cebola termina o volume com um capítulo intitulado "Onde se esconde a maior dor", que estabelece uma oposição com o capítulo inicial dedicado à felicidade. Exibia, assim, a pluralidade de alterações ao psiquismo normal, demonstrando como os doentes mentais poderiam ser os indivíduos mais felizes, e também os mais angustiados. Aproveitava uma vez mais para se referir à "trilogia dramática da vida": "nascer, viver, morrer" (Cebola, 1925, p.191). Embora reconhecesse que a dor era sentimento experimentado por todos os seres humanos, como consequência da constante transformação da matéria e da natureza, e da consciência da própria morte - "Cada pessoa escreve a sua história à sombra de um cipreste" (p.191) -, admitia que a dor mais profunda era a experimentada pelo "melancólico ansioso com delírio de imortalidade", uma vez que esse doente:

Tomado de inquietação e tristeza, acusa-se de pecados e crimes que não cometeu. Ouve, aterrorizado o ruido dos instrumentos da tortura que os algozes lhe preparam. Uma voz interior imperativamente lhe ordena que estrangule os próprios filhos, para os poupar à suprema desonra da sua pública execração. Sobressaltado, desconfiado de tudo e de todos, a insônia põe-lhe fogo no olhar alucinado (Cebola, 1925, p.192-193).

O desespero levava esses doentes a recusar o alimento, bem como a ponderar o suicídio, como forma de escapar à punição a que se julgavam condenados.

A angústia resultante da consciência permanente da inevitabilidade da morte foi um tema muitas vezes referido por Luís Cebola nas suas obras, em particular nas que foram escritas durante os últimos vinte anos da sua vida. A forma como representava os loucos nesse volume funcionava como metáfora para aquela que era a tragédia inerente ao milagre da vida humana. Os loucos existiam por contraste com os homens normais, respeitando a dualidade inerente ao universo: razão/emoção, bem/mal, felicidade/tristeza, luz/escuridão. 


\section{Considerações finais}

O volume de 1925, Almas delirantes, aplicava a ideia de dualidade e circularidade da existência aos doentes mentais, criaturas que, na sua própria experiência da vida, encenavam o drama da morte, ficando muitas vezes incapacitados de estabelecer comunicação com o mundo exterior e de se reconhecerem a si mesmos. Esse volume procurava restabelecer o seu lugar na comunidade dos sãos e demonstrar os resquícios de humanidade que se escondiam nesses homens, apesar da sua doença, cujo progresso era na época praticamente imparável. Cebola (1925, proêmio) afirmava justamente como ele tinha evoluído no seu contato com esses homens, emocionando-se com a sua tragédia, com o seu infortúnio e, por meio dessas circunstâncias, ia incrementando a sua coragem e ampliando o seu conhecimento acerca da pluralidade da natureza humana:

No convívio com as almas de esse mundo, abandonei todas as vaidades. Desci então ao abismo onde se esconde a noite; e de lá trouxe a coragem inalterável que desarma os perigos e amacia os obstáculos. ... Admirei estoicamente a explosão formidável das tragédias. Abrupta e tumultuariamente, o lodo subia do fundo a turvar a superfície das águas límpidas.

O volume demonstra que a perceção que Cebola tinha em relação aos doentes mentais ultrapassava a de simples objetos de estudo científico, constituindo antes um processo de identificação, empatia e compaixão. O livro permitia-lhe ainda divulgar o Museu da Loucura existente na CST e os registos escritos e pictóricos elaborados por alguns pacientes, colocando-o na posição de mensageiro desse universo fechado que era o asilo psiquiátrico, neste caso, a Casa de Saúde do Telhal. Cebola $(1925$, p.132) referia também nessa obra o periódico ergoterápico - um jornal escrito e editado pelos pacientes da CST - A Gazeta do Telhal. Durante a década de 1930, a edição desses periódicos foi bastante prolífica na CST. Tiveram início em 1931, sendo compostos por desenhos a tinta da china, aquarelas e alguns textos elaborados pelos pacientes. Todos tinham curta duração, limitando-se a um número muito reduzido de edições. Esses jornais eram incentivados pelo próprio Luís Cebola, como atividade de trabalho terapêutico, e a sua referência nessa obra é demonstrativa da importância que esses jornais tinham para o médico, bem como da vontade que tinha de partilhar algum do seu conteúdo e imaginário com os seus leitores.

Essa obra destacava-se das que eram publicadas pelos psiquiatras seus contemporâneos, como Sobral Cid ou Júlio de Matos, uma vez que não tinha a classe médica como públicoalvo, não pretendia descrever quaisquer teorias médicas ou práticas terapêuticas nem usava linguagem médico-científica. Era dedicada ao público geral, fazendo uso de uma linguagem metafórica e lírica por meio da qual Cebola pretendia expressar a angústia resultante da doença mental, sentida pelos próprios doentes bem como pelos seus familiares e médicos.

Cebola, adotando o papel de mensageiro dessas "almas delirantes", demonstrava, por um lado, o poder que a hierarquia da sua profissão lhe conferia. Como médico, ele filtrava e escolhia qual a versão dos doentes que mostrava ao seu público. Ao exercer a função de diretor clínico, tinha a possibilidade de decidir que cartas abandonavam a instituição, bem como quais as visitas autorizadas, gerindo mesmo a marcação delas. Poderia proibir que determinados familiares ou amigos do doente o visitassem. Por outro lado, nessa obra de 
1925, Cebola mostrava uma versão muito multifacetada do doente mental: alguém que, por um lado, não tinha o domínio total sobre a sua racionalidade nem sobre a sua moral, mas que preservava a capacidade de estabelecer raciocínios, sobre si e sobre o mundo, de gerar novas ideias, ainda que "delirantes", e que sob a alçada de alguém responsável e cientificamente competente - o psiquiatra - poderia ainda oferecer o seu contributo à sociedade, por meio da sua arte e da sua visão do mundo. O psiquiatra adquiria assim outra função: a de tornar inteligível o universo psíquico e ideativo dos doentes mentais, e selecionar quais as facetas do doente que podiam ainda permitir a sua ligação à sociedade. Nessa obra Cebola reforçava como era tênue a linha que delimitava a loucura da normalidade, contribuindo desse modo para destacar a importância do papel do psiquiatra na manutenção do equilíbrio da sociedade sua contemporânea.

\section{AGRADECIMENTO}

Este artigo tem por base a dissertação de doutoramento da autora (ver Pereira, 2015). O projeto foi financiado pela Fundação para a Ciência e Tecnologia de Portugal (SFRH/BD/69452/2010).

\section{NOTAS}

${ }^{1}$ O Hospital de Rilhafoles foi inaugurado a 13 de dezembro de 1848, nas instalações do antigo convento de São Vicente de Paula (Fernandes, 1984, p.255-256). De 1892 até ao seu assassinato, em 1910, Miguel Bombarda foi o seu diretor clínico, tendo aí introduzido a terapia por meio da prática de trabalhos agrícolas e melhorado as instalações hospitalares (Cid, 1925, p.9, 12; Fernandes, 1984, p.262). Após o assassinato de Miguel Bombarda, o Hospital de Rilhafoles passou a ser designado por Manicómio Bombarda, tendo Júlio de Matos (1856-1922) como diretor. Em 1922, sob direção de Sobral Cid (1877-1941), o hospital mudou o nome para Asilo Psiquiátrico Bombarda, e, em 1948 adquire a designação de Hospital Miguel Bombarda (Centenário..., 1949, p.50-57).

${ }^{2}$ Este editor, nascido em Braga, foi editor na Livraria Tavares Cardoso e Irmão e na Livraria Central, tendo sido um apoiante do movimento republicano e estando envolvido nos preparativos do 5 de Outubro de 1910 (Ribeiro, 1915, p.105). Editou autores nacionais como Gomes Leal (1848-1921), Albino Forjaz de Sampaio (1884-1949) ou Heliodoro Salgado (1861-1906). De Luís Cebola, de quem era amigo, editou sete obras: Almas delirantes (1925), História de um louco (1926), Psiquiatria social (1931), Sonetos e sonetilhos (1932), Enfermagem de alienados (1936), Psiquiatria clínica e forense (1940), Democracia integral: origem e evolução (1951).

${ }^{3}$ Este advogado, amigo íntimo do poeta Fernando Pessoa, tendo-lhe até sugerido a alteração do nome do seu livro Mensagem, e ao qual o poeta terá elaborado diversos mapas astrológicos, escreveu vários artigos em jornais da época entre 1917 e 1919, que, posteriormente reuniu no volume Um lance, publicado em 1919. Muitos desses artigos recorriam à citação de excertos de entrevistas que este teria feito a magistrados de renome. Em todos esses textos, e nas críticas relativas ao decreto de 11 de maio de 1911, fica patente a polêmica que existia entre os homens do direito e os médicos, especialmente os psiquiatras. As críticas a esta lei, escrita por Júlio de Matos, apoiavam-se na inconstitucionalidade da mesma, uma vez que esta se encontrava em conflito com um dos artigos da constituição de 21 de agosto de 1911, o que alegava a incapacidade legislativa dos médicos. Da Cunha Dias, nome com o qual o advogado assinava, era natural de Sintra e nascera numa família de classe média. Estudara direito em Coimbra, frequentando todavia as tertúlias e cafés de Lisboa - Brasileira, Martinho da Arcada e Café Montanha -, onde conheceu Fernando Pessoa, com o qual partilhava o fascínio pelo ocultismo. É conhecida a sua relação tumultuosa com o pai, homem violento, que teria levado o irmão mais novo a cometer suicídio. Após ter abandonado a sua mulher, o sogro e o seu pai, convencidos de que ele sofria de doença mental, terão requerido o seu internamento em manicômio. Luís Cebola encontrava-se entre os quatro médicos que terão atestado a loucura de Da Cunha Dias, em conjunto com Júlio de Matos, António Flores e Manuel de Vasconcelos (Barreto, 2012, p.70-138).

${ }^{4} \mathrm{O}$ neurologista e psiquiatra António Flores foi o primeiro diretor clínico do Hospital Júlio de Matos, inaugurado em 1942, e também docente da Faculdade de Medicina da Universidade de Lisboa. Em 1949, juntamente com Barahona Fernandes, fundou a primeira revista médica portuguesa dedicada exclusivamente à psiquiatria, os Anais Portugueses de Psiquiatria (Flores, 1953, p.4). Em 1945, Flores 
impulsionou a promulgação de uma nova lei, regulando a assistência psiquiátrica, que pretendia definir uma nova orientação para a especialidade médica, abrangendo a profilaxia, terapêutica e pedagogia, bem como visando ao aumento do número de leitos nos hospitais. Este documento previa igualmente que o tratamento dos doentes mentais pudesse ser realizado em regime ambulatório, em hospitalização, em assistência no domicílio, bem como por meio da colocação familiar. Decretando igualmente a possibilidade de internamento em regime aberto, por meio do qual os doentes não perdiam as garantias que lhes eram concedidas nos hospitais gerais (Fernandes, 1950, p.316-317).

${ }^{5} \mathrm{O}$ alienista Júlio de Matos foi catedrático de psiquiatria na Faculdade de Medicina da Universidade do Porto e diretor do Manicômio Bombarda entre 1911 e 1923. Exerceu grande influência nos governos da Primeira República, tendo sido o impulsionador, bem como o projetista, em 1913, do hospital psiquiátrico do Campo Grande, denominado, posteriormente, em sua homenagem, e que apenas abriria ao público em 1942 (Fernandes, 1984, p.277, 298). Em maio de 1911, foi promulgado um decreto, redigido por este psiquiatra, regulando a assistência psiquiátrica, que apresentava diversas reformas ao sistema existente, entre as quais previa a criação de sete novos hospitais psiquiátricos no país bem como de dez colônias agrícolas (Portugal, 13 maio 1911). Publicou vasta obra da especialidade, de elevada relevância para a consolidação da psiquiatria como especialidade clínica em Portugal, da qual se destaca o manual Elementos de psiquiatria (1911), o livro de texto psiquiátrico mais consultado na área da psiquiatria durante as duas décadas subsequentes à sua publicação, de acordo com Barahona Fernandes (1984, p.277-282).

${ }^{6}$ Sobre as duas obras de Luís Cebola aqui referidas: em Estado Novo e República (1955), por meio do uso de vocabulário clínico e científico, corroborado pela sua vasta experiência enquanto psiquiatra, Cebola conferia autoridade às suas visões políticas - defesa do regime republicano e democrático -, bem como às críticas estabelecidas em relação ao regime do Estado Novo. É uma obra moralizadora e propagandista, por meio da qual Cebola popularizava as ciências psiquiátricas e em simultâneo validava o regime republicano e os seus anseios sociopolíticos. No volume de contos Quando desci ao inferno: contos psicopatológicos (1956), a escrita encontra-se marcada pelo forte entrecruzamento de discursos, onde é impossível discernir fronteiras claras entre a teorização etiológica e clínica e o seu forte posicionamento ideológico e político. É uma obra de caráter fortemente moralizador e propagandístico, com o objetivo de despertar nos leitores um sentimento de ameaça e de desconfiança a respeito de certas instituições e tipos de pensamento, como o governo do Estado Novo e a Igreja católica. Ver Pereira (2015).

${ }^{7}$ Ver por exemplo Psiquiatria social (1931) ou Quando desci ao inferno: contos psicopatológicos (1956). Este assunto encontra-se desenvolvido no capítulo 3 de Pereira (2015).

${ }^{8}$ A revista Hospitalidade: Crônica Trimestral dos Irmãos de São João de Deus, uma publicação interna da Ordem Hospitaleira dos Irmãos de São João de Deus, teve a sua primeira edição em 1936 e é ainda publicada na atualidade. Essa publicação continha, nas primeiras edições, as estatísticas referentes aos tratamentos psiquiátricos aplicados nessa instituição, bem como estatísticas relativas às entradas e saídas dos pacientes. Todas as edições contêm notícias sobre o ambiente hospitalar e sobre eventos da comunidade religiosa, contêm ainda artigos diversos sobre a assistência psiquiátrica. Essa publicação é de elevada relevância para melhor conhecer a evolução do ambiente hospitalar da CST, assim como para compreender quais as concepções de doença mental e de tratamentos que eram privilegiadas pela instituição.

9 "Hipomania", termo proposto pelo psiquiatra berlinense Emanuel Ernst Mendel (1805-1877), designava formas menos intensas de mania. Os indivíduos assim diagnosticados começavam por se entregar a uma vida boêmia, exibindo uma personalidade marcada por um egotismo moral, bem como por um excesso de autoconfiança. Mendel acrescentava ainda que esses indivíduos apenas se preocupavam em satisfazer os seus desejos e impulsos. Antes do trabalho de Mendel, o termo "mania" era apenas utilizado para designar demência com excessiva agitação motora, mas para esse psiquiatra a mania podia significar também agitação dos centros nervosos, gerando excitabilidade ao nível das ideias (Shorter, 2005, p.132-133).

${ }^{10}$ A designação psiquiátrica de "demência paralítica", cujo quadro sintomático se iniciava com perturbações do foro psiquiátrico seguidas de convulsões e paralisia, correspondia, na verdade, ao terceiro estádio da infecção sifilítica. Era também conhecida como "paralisia geral" ou "paralisia progressiva". Em 1905, August Wassermann (1866-1925), médico no Instituto Koch para doenças infecciosas localizado no Hospital Charité, em Berlim, descreveu na revista Deutsche Medizinische Wochenschrift um método que permitia diagnosticar sífilis, procedendo à análise do líquido cefalorraquidiano, tendo publicado mais tarde, no mesmo ano, um artigo descrevendo que se verificavam resultados positivos usando esse teste na maioria dos doentes sofrendo de paralisia geral. Em 1913, Hideyo Noguchi e J.W. Moore descobriram a existência de espiroquetas no tecido cerebral de doentes com paralisia geral, o que terá provado definitivamente a teoria longamente aceite de que havia uma ligação direta entre a sífilis e a paralisia geral, sendo a segunda uma consequência da evolução da primeira (Shorter, 2005, p.73, 193, 194). 


\section{REFERÊNCIAS}

BARRETO, José.

O mago e o louco: Fernando Pessoa e Alberto da Cunha Dias. Pessoa Plural, v.1, n.1, p.70-138. 2012.

BORGES, Augusto Moutinho et al. Um republicano no convento. Cadernos do Ceis20, n.13. 2009.

CARVALHO, António Meira de.

Tratamentos no Telhal pelos anos 30. In: Gameiro, Aires (Dir.). Casa de Saúde do Telhal $1^{\circ}$ Centenário, 1893-1993: documentos históricos e clínicos. Lisboa: Editorial Hospitalidade. [1943] 1993.

CARVALHO, António Meira de.

[Nota]. Hospitalidade: Crônica Trimestral dos Irmãos de São João de Deus em Portugal, v.171, p.127. 1980.

CEBOLA, Luís.

Memórias de este e do outro mundo. Lisboa: Edição do autor. 1957.

CEBOLA, Luís.

Quando desci ao inferno: contos psicopatológicos. Lisboa: Edição do autor. 1956.

CEBOLA, Luís.

Estado Novo e República. Lisboa: Edição do autor. 1955.

CEBOLA, Luís.

Elogio da laborterapia. Hospitalidade: Crônica

Trimestral dos Irmãos de São João de Deus em

Portugal, v.36, p.160-163. 1945.

CEBOLA, Luís.

Psiquiatria social. Lisboa: Livraria Gomes de Carvalho Editor. 1931.

CEBOLA, Luís.

Almas delirantes. Lisboa: Livraria Central Editora. 1925.

CEBOLA, Luís.

A mentalidade dos epiléticos. Tese (Doutorado em Estudos Médicos) - Escola Médico-Cirúrgica de Lisboa, Lisboa. 1906.

CENTENÁRIO...

Centenário do Hospital Miguel Bombarda (antigo Hospital de Rilhafoles). Lisboa: Edição do Hospital Miguel Bombarda. 1949.

CID, Sobral.

O professor Miguel Bombarda: a sua carreira e a sua obra de alienista. Lisboa: Faculdade de Medicina de Lisboa. 1925.

DIÁRIO DE NOTÍCIAS.

Diário de Notícias, p.2. 22 jul. 1925.
DIAS, Alberto da Cunha.

Um lance. Coimbra: Arco de Almedina. 1919.

FERNANDES, Barahona.

A psiquiatria em Portugal. Lisboa: Roche. 1984.

FERNANDES, Barahona.

A psiquiatria em Portugal. Anais Portugueses de Psiquiatria, n.2, p.314-344. 1950.

FLORES, António.

Orientação do Hospital Júlio de Matos. Anais

Portugueses de Psiquiatria, n.5, p.1-18. 1953.

FOUCAULT, Michel.

History of madness. Tradução Jean Khalfa, Jonathan Murphy. New York: Routledge. 2009.

GAMEIRO, Aires.

Evocação de um médico esquecido: o Dr. Luís Cebola, pioneiro da ocupação ergoterápica na Casa de Saúde do Telhal, da Ordem Hospitaleira de São João de Deus. In: Marques, António Lourenço (Dir.). Medicina na Beira Interior da préhistória ao século XXI, v.23. Castelo Branco: [s.n.] p.126-134. nov. 2009.

LAVAJO, Joaquim Chorão.

Ordem Hospitaleira de S. João de Deus em Portugal, 1892-2002. Lisboa: Editorial Hospitalidade. 2003.

O MINISTRO....

O ministro da Justiça e as congregações religiosas: visitas ao Hospício do Telhal e da Idanha e à Escola Penha-Longa. Ilustração Portuguesa, v.244. 24 out. 1910.

O SÉCULO.

O Século, p.2. 2 set. 1925.

PEIRY, Lucienne.

Art brut: the origins of outsider art. Paris: Flammarion. 2001.

PEREIRA, Denise.

Visões da psiquiatria, doença mental e república no trabalho do psiquiatra Luís Cebola (1876-1967): uma abordagem histórica nas encruzilhadas da psiquiatria, ideologia política e ficção, em Portugal, na primeira metade do século XX. Tese (Doutorado) - Faculdade de Ciências e Tecnologia, Universidade Nova de Lisboa, Lisboa. Disponível em: http://run.unl.pt/ handle/10362/16309. Acesso em: 9 nov. 2017. 2015.

\section{PORTUGAL.}

Decreto de 11 de maio. Autorizando a criação de novos manicômios e de colônias agrícolas para alienados, e regulando os respectivos serviços. Diário do Governo, n.111. Disponível em: https:// dre.pt/application/file/596413. Acesso em: 1 dez. 2015. 13 maio 1911. 
PRINZHORN, Hans.

Artistry of the mentally ill. Berlin: Springer. 1972.

RIBEIRO, Armando.

A Revolução Portuguesa, v.2: em plena revolução. Lisboa: João Romano Torres. 1915.

SERRANO, José António (Dir.).

A Escola Médico-Cirúrgica de Lisboa em 1899-1900, Anuário. Lisboa: Imprensa Nacional. 1907.
SERRANO, José António (Dir.).

A Escola Médico-Cirúrgica de Lisboa em 1899-1900, Anuário. Lisboa: Imprensa Nacional. 1900.

SERRÃO, Joaquim Veríssimo.

História de Portugal, v.11: a Primeira República (1910-1926): história política, religiosa, militar e ultramarina. Lisboa: Verbo. 1995.

SHORTER, Edward.

A historical dictionary of psychiatry. New York: Oxford University Press. 2005.

\section{$\rightarrow \rightarrow \rightarrow<<<$}

